\title{
ZONA DE TURBULENCIA: ARTE EN NICARAGUA, DE LA REVOLUCIÓN AL NEOLIBERALISMO. RAÚL QUINTANILLA ARMIJO. SAN JOSÉ: TEOR/ÉTICA, 2018
}

Adriana Collado Chaves

Recibido: 11/09/19 - Aceptado: 19/09/19

Nicaragua, Arte Contemporáneo y Raúl Quintanilla Armijo. Triada indivisible caracterizada por la resistencia. Con más vidas y más garras que un gato arisco. Así al menos lo he experimentado yo. Y ahora que he concluido la lectura de este libro, confirmo que ese ser tricéfalo solo puede sobrevivir así: arañando cualquier autoridad que intente domesticarlo, saltando siempre a un abismo con el instinto de caer en cuatro patas y con la esperanza herida pero parda, para camuflarse en las largas noches en las que su patria no parece ver la luz.

El libro retrata una especie de trinomio algebraico formado por "pensador/ plástica/país" donde cada "P" le suma o le resta algo a la otra según pasan las décadas. Los textos, un decálogo en orden cronológico, inician con un tono de esperanza juvenil, que celebra una tierra prometida cuyos muros se visten de luchas, victorias y anhelos: es el triunfo de la Revolución sandinista. Concluye con una esperanza tozuda, de quien ha transitado un largo desierto de ilusiones y cree que aún es posible no quemarse en el infierno prometido: el rapto de esa misma Revolución, casi cuarenta años después, a manos de algunos de sus propios protagonistas. $Y$ en ese giro dramático, tanto en el sueño como en la pesadilla, pareciera que hay una sola cosa que sigue creyendo el artista: que vendrá una generación nueva, que creará un arte nuevo y hará de ese arte la última trinchera posible para vencer dictaduras y sumisiones estéticas y políticas.

Esta publicación pertenece a la serie Escrituras Locales. Posiciones críticas desde América Central, el Caribe y sus diásporas, proyecto editorial de TEOR/éTica que busca reunir el pensamiento de intelectuales cuya labor ha sido clave para el devenir de las prácticas artísticas contemporáneas en la región. Desde esta perspectiva se aborda el aporte de Quintanilla Armijo. El editor escoge como encuadre diez textos: cuatro de la década de 1980, tres de los años 1990 y dos de inicio del siglo XXI. El tomo incluye una entrevista realizada en San José, en julio del 2018, donde la mirada actual del artista amplía el alcance y la capacidad del lector para interpretar cada ensayo de acuerdo a su época. 
Los escritos presentan una panorámica de casi medio siglo de arte, política e historia de vida en Nicaragua. El hilo empieza con la contextualización de la lucha sangrienta de los años 1970, el régimen de la familia Somoza y los antecedentes de la plástica nacional nicaragüense y se corta en el escenario de Nicaragua en el 2018, con la criminalización de las protestas callejeras por parte del gobierno de Daniel Ortega y de Rosario Murillo.

Hace poco realicé un trabajo curatorial con la obra de Raúl Quintanilla Armijo, razón por la cual estudié parte de sus creaciones artísticas, revisé la producción editorial de seis de sus revistas y me aproximé al legado de su trabajo en gestión cultural. Dicho esto, me alegra confesar que nunca había leído ninguno de los textos de este compendio. Aunque la experiencia no ha estado exenta de sorpresas (sobre todo el tono institucionalizado de sus primeros textos), acabo corroborando dos apreciaciones fundamentales que tenía respecto al estilo personal de ser y de hacer de Raúl Quintanilla Armijo. Por una parte, constato que él y su archivo son una especie de arcanos mayores, cargados con un arsenal de documentos que constituyen una valiosa mina de información para estudiar la historia del arte contemporáneo en Nicaragua, no obstante, “el programa" para acceder y clasificar todos esos datos, tan solo existe y corre en la cabeza de Quintanilla Armijo (y nadie sensato podría escudriñar ahí por mucho tiempo). Por otra parte, corroboro que su fuerza como editor, escritor, curador, artista y promotor radica en su capacidad para saberse agente y vocero de un colectivo. No solo sus composiciones artísticas son una obra libre y abierta; construida, destruida y reconstruida con el ensamblaje de las creaciones de otros, sino que su aporte como editor y promotor cultural opera bajo esa misma lógica: abriendo espacios sin reglas, sin condiciones y sin jerarquías, para que se junten los que puedan y se muestren los que quieran. Incluso, en la entrevista nos deja saber que, no existiendo un colectivo robusto que aportara textos a un número de la revista "ArteFacto", creó tres personajes para no debutar en solitario: Alejandra Urdapilleta, Anita Guillete y Paco Pico, sus pseudónimos.

Ahora paso a los ensayos.

Los primeros cuatro, a mi juicio, conforman una especie de manifiesto que tiene por común denominador exaltar el rol que los artistas debían asumir para que cuajaran los proyectos de transformación cultural, nacidos al amparo del triunfo revolucionario.

Los dos relatos iniciales celebran el avance de los proyectos culturales puestos en marcha en la primera parte de la década de 1980. Su leitmotiv apunta a todo "lo nuevo" en la "Nueva Nicaragua”. De esta manera se informa que en 1985 se construía la nueva escuela de muralismo en los terrenos que otrora fueran una hacienda de Somoza y que habían pasado a ser del Ministerio de Cultura. Se recuerda que, con el triunfo de la revolución en julio de 1979, el Padre Ernesto Cardenal, Ministro de Cultura, celebró una reunión con artistas en la Escuela Nacional de Artes Plásticas -ENAP- y que la mayoría se inclinaron por "iniciar un muralismo nacional, de carácter popular 
y revolucionario" (22). Sin embargo, por falta de conocimientos, los primeros murales se estropearon. Entonces, gracias a un intercambio llegaron tres italianos a enseñar la técnica, los artistas nicaragüenses retomaron el interés y se echó a andar el proyecto de la escuela: "Y era necesario, pues el muralismo es un arte monumental y público... de las calles... donde el pueblo esté en el poder, es decir un arte con todas las posibilidades y el deber de darse en la nueva Nicaragua (23).

El segundo ensayo, escrito junto a Juan Rivas, fue presentado en 1987 en el Primer Foro de la Plástica Nacional. Repasa los orígenes del arte moderno nicaragüense con el pintor Rodrigo Peñalba formando a la generación de artistas que luego se aglutinó en los grupos Praxis y Gradas, agrupaciones que en la década de 1960 se convirtieron en la vanguardia artística e intelectual vinculada al Frente Sandinista de Liberación Nacional (FSLN). Después vino la generación de "transición” de 1970 y en la década de 1980 se asiste a la apertura de espacios para la "Nueva Generación", con el apoyo de la Asociación Sandinista de Trabajadores de la Cultura (ASTC) y de los certámenes nacionales de artes plásticas. Se insta a "todos nosotros, vieja, intermedia y nuevas generaciones" (37) a ser originales en la búsqueda de una identidad para la plástica nacional, sustentándose para ello en "una discusión abierta, fraterna y veraz" (37) fundamentada en la crítica y la teoría.

En línea con la premisa anterior, Quintanilla Armijo presenta en ese mismo foro un texto en el que advierte que, aunque "los medios de producción artística no son propiedad exclusiva de una elite de artistas e intelectuales" (47) ha aparecido "una plaga de seudoartistas" (47) que copian el lenguaje de los primitivistas nicaragüenses sin serlo, banalizando la raíz sociocultural de esa producción hasta convertirla en un souvenir fácilmente consumible por un frívolo mercado amante del exotismo: "nuestra pintura primitiva nace verdaderamente como fenómeno popular y democrático, único en América Latina, en las experiencias didáctico-pedagógicas de Solentiname" (43) insiste Quintanilla Armijo.

En el cuarto artículo, escrito junto a Patricia Belli y Raquel Quezada, publicado en "Ventana", suplemento cultural del periódico sandinista "Barricada", se evidencia ya una fisura respecto a la narrativa anterior, quedando claro que no había ni tanta actitud crítica, ni tanta fraternidad entre las distintas generaciones de artistas plásticos nicaragüenses, y que en cambio había un "estancamiento" (53) y una "crisis" (51), porque la mayoría de creadores o repetían la tradición iniciada por el grupo Praxis, o emulaban corrientes occidentales como el expresionismo, cayendo en una autocomplacencia decadente. Aparte de ello, sabían que los conservadores no los estaban tomando en serio, pero acaban advirtiendo que no estaban dispuestos a dar ni un paso atrás: “El resto de las experiencias plásticas, o sea aquellas realizadas fuera de estos criterios "artísticos" imperantes (instalaciones, acciones y montajes-ensambles) son juzgadas muy mal... como payasadas... inmerecedoras de la más mínima atención y mucho menos reconocimiento... Conclusión. No lo lograrán" (60). 
Y como si no hubiese sido ya lo bastante difícil luchar por la renovación de lenguajes y formas de expresión de la plástica en los años del triunfo de la Revolución sandinista, la situación en la década siguiente sí que dio un golpe de gracia a los ideales de esta generación de artistas, cuando en 1990 el FSLN perdió las elecciones y se inauguró la era del proyecto neoliberal, que trajo consigo un sistemático proceso de invisibilización: se borraron los murales de la ciudad, la escuela de muralismo se extinguió junto con los certámenes, con la ASTC y la Unión de Artistas Plásticos. La ENAP - que durante dos años había sido dirigida por Quintanilla Armijo- no logró renovar su malla curricular ni establecer un método sostenible de retroalimentación con los artistas comunitarios que producían desde los Centros Populares de Cultura, espacios que también desaparecieron. Feneció la cruzada del Taller de Gráfica Experimental y el Museo de Arte Contemporáneo Julio Cortázar, del que Quintanilla Armijo también fue director y cuya colección se había conformado con donaciones de artistas de gran prestigio internacional, también fracasó. El tiempo del "sálvese quien pueda" había llegado para quedarse. La nueva generación de artistas, golpeada por la indignación y el desasosiego, se lamió las heridas un rato y luego asumió su galla desde la orfandad, reagrupándose para existir e insistir en crear "al margen" de las políticas gubernamentales, de las pululantes galerías y de los artistas conservadores que reclamaron su cetro como los grandes maestros del arte nicaragüense. Y así fue como nació el espacio autogestionario de la "ArteFactoría" y una serie de revistas que a lo largo de años Quintanilla Armijo continuó produciendo como parte de colectivos cuyos integrantes fueron mutando con el paso del tiempo.

La única legitimación existente llegó de afuera. Historiadores y teóricos norteamericanos como David Craven, que se habían acercado desde tiempos de la Revolución, continuaron estando presentes y siendo aliados después de 1990. Luego llegaron otras miradas, como la de curadora Joanne Bernstein, que con una lectura asociada a la guerra creó la exposición "Tierra de tempestades. Arte nuevo desde Guatemala, El Salvador y Nicaragua", exhibida en Preston, Inglaterra. Llegó también el reconocimiento al interno de la misma región, cuando Virginia Pérez Ratton y Rolado Castellón abrieron un canal de diálogo desde el Museo de Arte y Diseño Contemporáneo de Costa Rica, que se gestó con la muestra "Mesótica II/ Centroamérica re-generación". Paulatinamente se abrieron nuevos espacios de articulación como TEOR/éTica en Costa Rica, ARPA de Panamá, MUA de Honduras y La Curandería de Guatemala. También sucedió que ante la ausencia de políticas de promoción e inversión gubernamental para las artes visuales, la iniciativa privada de la Bienal de Artes Visuales de Nicaragua y los espacios expositivos de la Fundación Ortiz Gurdian representaron un importante impulso... aunque en el nuevo orden de cosas esa Bienal ha quedado suspendida indefinidamente, lo mismo que, ante los sucesos del 2018, ha debido quedar en pausa la actividad de "Mácula", el último proyecto cultural colectivo del que participa activamente Quintanilla Armijo. 
Los últimos seis ensayos, sintetizados en los dos párrafos anteriores, son por tanto una zambullida en la descomposición y reconfiguración de las prácticas artísticas en Nicaragua, desde 1990 hasta la fecha.

Concluyo con una reflexión expuesta por el autor al referirse al trabajo de la artista Patricia Belli, de quien decía había logrado crear "esta nueva arena del conflicto humano más privada y personal... un arte cuya dimensión política, subversiva y -por qué no- revolucionaria es igual, sino más intensa, que el arte "comprometido" de las anteriores generaciones vociferantes" (138). De aquí recojo esta idea: quien quiera crear arte contemporáneo hoy en Nicaragua, ha de tener bien internalizado que la única revolución posible y sin tregua, es esa que cada uno lleva por dentro. Ese es el corolario que me queda de un libro que se lee fluido y de un escritor talentoso a quien alguna vez Carlos Martínez Rivas nombró “Armhijo” (MADC 17).

\section{Bibliografía}

Museo de Arte y Diseño Contemporáneo (MADC). Artefacto: antología. San José, Costa Rica: 2018.

Adriana Collado Chaves. Costarricense. Bachiller en Historia del Arte por la Universidad de Costa Rica, Máster en Patrimonio Mundial y Proyectos Culturales para el Desarrollo por la Universidad de Turín, Italia y la Universidad de Barcelona, España, Máster en Administración de Negocios por INCAE Business School. Ha sido Directora de Cultura del Ministerio de Cultura y Juventud (2005-2010), Directora del Teatro Nacional de Costa Rica (2010-2014), Curadora del Museo de Arte y Diseño Contemporáneo -MADC- (2016-2019). Desde 2015 realiza labores Ad honorem de comunicación cultural en el Programa Desayunos de Radio Universidad de la UCR. Actualmente es Jefa del Departamento de Promoción Regional de la Dirección de Cultura del MCJ. Es editora de cinco catálogos correspondientes a curadurías de su autoría, todos bajo el sello MADC, siendo la última de estas publicaciones: No tiene nombre. Unspeakable. Raúl Quintanilla Armijo + Mácula/SBB (2018).

Correo electrónico: collado.adriana@gmail.com

ORCID: 0000-0002-5760-4302 
